\title{
A behavioural intervention incorporating specific glycaemic index goals improves dietary quality, weight control and glycaemic control in adults with type 2 diabetes
}

\author{
Carla K Miller ${ }^{1, *}$, Amy Headings ${ }^{1}$, Mark Peyrot ${ }^{2}$ and Haikady Nagaraja ${ }^{3}$ \\ 'Department of Human Nutrition, Ohio State University, 1787 Neil Avenue, 350 Campbell Hall, Columbus, \\ $\mathrm{OH}$ 43210, USA: ${ }^{2}$ Department of Sociology, Loyola University Maryland, Baltimore, MD, USA: ${ }^{3}$ Department of \\ Statistics, Ohio State University, Columbus, OH, USA
}

Submitted 13 July 2010: Accepted 9 January 2011: First published online 28 February 2011

\begin{abstract}
Objective: A lower glycaemic index (GI) diet is associated with a reduction in glycosylated $\mathrm{Hb}\left(\mathrm{HbA}_{1 \mathrm{c}}\right)$ in people with diabetes. Yet, little research has been conducted to determine the effects of specific goals regarding consumption of low GI (LGI) foods on diabetes outcomes. The present study evaluated a behavioural intervention on dietary intake, weight status and $\mathrm{HbA}_{1 \mathrm{c}}$, which included a goal to consume either six or eight servings of LGI foods daily.

Design: A parallel two-group design was used. Following the 5-week intervention, participants were randomly assigned to the group of six ( $n 15)$ or eight ( $n$ 20) servings of LGI foods daily and followed up for 8 weeks. Dietary intake was assessed using the mean of $4 \mathrm{~d}$ food records.

Setting: A metropolitan community in the USA.

Subjects: Individuals aged 40-65 years with type 2 diabetes of $\geq 1$ year and $\mathrm{HbA}_{1 \mathrm{c}} \geq 7 \cdot 0 \%$ were eligible.

Results: There was no significant difference between goal difficulty groups with regard to GI servings at the end of the study. However, mean consumption of LGI foods increased by $2 \cdot 05$ (SE 0.47 ) and 1.65 (SE 0.40 ) servings per $4184 \mathrm{~kJ}$ in the six $(P<0 \cdot 001)$ and eight $(P<0 \cdot 001)$ LGI serving groups, respectively. For all participants combined, there were significant decreases in mean $\mathrm{HbA}_{1 \mathrm{c}}(-0.58$ (sE 0.21)\%; $P=0 \cdot 01$ ), weight $(-2 \cdot 30 \quad$ (sE $0 \cdot 78) \mathrm{kg} ; P=0 \cdot 01)$, BMI $\left(-0 \cdot 80 \quad(\right.$ sE $0 \cdot 29) \mathrm{kg} / \mathrm{m}^{2}$; $P=0 \cdot 01)$ and waist circumference $(-2 \cdot 36($ SE $0 \cdot 81) \mathrm{cm} ; P=0 \cdot 01)$.

Conclusions: An intervention including a specific goal to consume six to eight servings of LGI foods daily can improve diabetes outcomes. Clinicians should help patients set specific targets for dietary change and identify ways of achieving those goals.
\end{abstract}

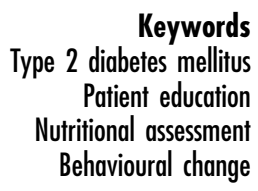

Medical nutritional therapy is an integral component of diabetes self-management. A diet that promotes healthy food choices, weight management and optimal glycaemic control is recommended for people with diabetes ${ }^{(1)}$. Both the quantity and type of carbohydrate consumed affect dietary quality and postprandial glucose excursions, and a diet that considers the glycaemic index (GI) and glycaemic load (GL) may provide additional benefits for diabetes management beyond that observed when total carbohydrate is considered alone ${ }^{(1,2)}$. For example, a recent review of nine randomized controlled trials found that fasting plasma glucose values were significantly lower, HDL cholesterol was 3\% higher and serum TAG was $6 \%$ lower on low GI (LGI) compared with high GI (HGI) diets ${ }^{(3)}$. Similarly, a meta-analysis in individuals with diabetes found a reduction in glycosylated $\mathrm{Hb}$ $\left(\mathrm{HbA}_{1 \mathrm{c}}\right)$ following an LGI diet ${ }^{(4)}$.
Goal setting is widely used in clinical care to assist patients in identifying target dietary goals to improve eating habits and self-management of diabetes ${ }^{(5)}$. Effective goals focus one's effort and can provide motivation for change ${ }^{(6)}$. Epidemiological studies report that an LGI diet (median GI of 54 when glucose equals 100) is associated with reduced risk for certain chronic diseases ${ }^{(7)}$. However, it is difficult for consumers to translate findings regarding disease risk into practical dietary goals or to calculate GI values for meals consumed.

Goal-setting research has shown that performance improves when people try to attain specific goals rather than vague goals, easy goals or no goals at all ${ }^{(6)}$. Most prior GI studies encouraged participants to substitute higher GI foods with lower GI foods but did not provide specific serving recommendations as goals for change ${ }^{(8-11)}$. Furthermore, goal-setting research suggests that goals 
should be relatively difficult to achieve in order to promote behavioural change ${ }^{(6)}$. The level of difficulty should be challenging enough to promote change but not be so difficult that the goal is perceived to be impossible. No prior research has evaluated appropriate goal difficulty regarding dietary GI. On the basis of previous research ${ }^{(8)}$ and sample menus created a priori, we estimated that six to eight servings of LGI foods daily would achieve a dietary GI of 54-55 and was a reasonable level of difficulty for a free-living population.

Therefore, the purpose of the present study was to evaluate the effect of two specific goals regarding GI on changes in dietary intake, weight management and glycaemic control in adults with type 2 diabetes. It was hypothesized that participants randomized to the group with a more difficult goal (eight servings of LGI foods daily) would achieve greater change in outcomes than those randomized to the group with a less difficult goal (six servings of LGI foods daily).

\section{Experimental methods}

\section{Eligibility criteria}

Individuals aged 40-65 years diagnosed with type 2 diabetes for $\geq 1$ year with an $\mathrm{HbA}_{1 \mathrm{c}}$ value of $\geq 7 \%$ and not requiring insulin therapy were eligible. The decline in cognitive function in middle-aged diabetic adults in previous research was greater than that in adults without diabetes ${ }^{(12)}$. Thus, a score of $<20$ on the mini-mental state examination ${ }^{(13)}$ or prior instruction in GI were criteria for exclusion. Participants were recruited through newspaper and electronic classified advertisements, employee newsletters, health fairs, medical practices, neighbourhood health centres and flyers. All study methods were approved by the institutional review board at the sponsoring institution and participants provided written informed consent.

\section{Research design}

A randomized parallel two-group design was used. Participants were assigned to a goal of either six or eight servings of LGI foods daily. One serving of an LGI food was defined as the amount of food in one serving on the Nutrition Facts Panel on food labels in the USA ${ }^{(14)}$. This definition concurred with the serving size information presented during the intervention.

Following recruitment, participants completed baseline data collection and then attended a 5-week nutritional intervention. Following the intervention, participants met individually with a dietitian from the University Clinical Research Center (CRC) to receive their randomization assignment. During this visit, the CRC dietitian helped participants target dietary changes to achieve their goal. Participants applied the assigned goal to their own eating patterns and identified ways to substitute LGI foods for higher GI foods on the basis of their personal food preferences; specific menus were not provided. Participants were followed up for approximately 8 weeks. Midway through this 8-week period, participants met individually with the CRC dietitian a second time to assess their progress.

Participants were asked to self-monitor their diet and blood glucose at least $4 \mathrm{~d} /$ week during the 8-week monitoring period to help them determine how well they were meeting their goal. Monitoring forms and booklets with the GI value of commonly consumed foods were provided to participants. One intervention session provided training on how to maintain food records; the training included the estimation of portion sizes using common household measures and the details to record foods purchased and preparation methods. Participants returned their records to the study dietitian who reviewed the records and provided standardized feedback on the number of LGI food servings consumed. The study dietitian, who coordinated data collection and feedback, was blinded to goal assignment and was not affiliated with the CRC. Final data collection occurred at study end following the 8-week monitoring period.

\section{The nutritional intervention}

The nutritional intervention included five group educational sessions led by a registered dietitian. Each session was approximately $1.5 \mathrm{~h}$ long and included six to ten participants. The sessions addressed the concept of GI, the relationship between dietary intake and postprandial glucose excursions, factors influencing the GI value of foods, strategies for substituting low for higher GI foods, serving size and portion control, dietary and glucose self-monitoring and approaches for maintaining behavioural change. Information on carbohydrate counting or other meal planning methods was not included since the intervention goals were specific to dietary GI.

\section{Study outcomes}

\section{Dietary outcomes}

All outcomes were measured at baseline and at study end. Participants completed a $4 \mathrm{~d}$ food record (three weekdays and one weekend day), and these records were entered into Nutrient Data Systems for Research (NDS-R, version 2008; Nutrition Coordinating Center, University of Minnesota, Minneapolis, MN, USA) to assess energy and nutrient intakes, GI, GL and food servings consumed. GI values are expressed relative to glucose (glucose $=100$ ). From the dietary records, foods were categorized into one of 166 subgroups within nine main food groups; subgroups were automatically generated from the NDS-R database. Mixed dishes were disaggregated into ingredients for correct placement into subgroups. Food subgroups were combined into categories for analyses. The number of servings consumed was based on the $4 \mathrm{~d}$ mean intake. In general, many whole fruits, vegetables (except 
white potatoes), pasta, dairy products, nuts and seeds are LGI foods ${ }^{(15)}$. These foods were used to quantify the number of servings of LGI foods consumed. LGI foods are defined as having a value of $<56$ and HGI foods have a value of $\geq 70^{(16)}$. Nutrient intakes and food servings were quantified per $4184 \mathrm{~kJ}(1000 \mathrm{kcal})$ to control for energy intake.

\section{Anthropometric outcomes and glycosylated $\mathrm{Hb}$}

Height was measured using a wall-mounted stadiometer and was measured to the nearest $0 \cdot 1 \mathrm{~cm}$. Weight was measured at baseline and at study end and recorded to the nearest $0 \cdot 1 \mathrm{~kg}$ using a digital scale (Healthometer Professsional Products, Bridgeview, IL, USA) with participants wearing light clothing and no shoes. BMI, which measures weight adjusted for height $\left(\mathrm{kg} / \mathrm{m}^{2}\right)$, was calculated. Waist circumference measurements were obtained following standardized procedures in the National Health and Nutrition Examination Survey ${ }^{(17)}$. All anthropometric measurements were taken twice and the mean of the two measurements was used in the analysis. An overnight $12 \mathrm{~h}$ fasting blood sample was drawn by venepuncture. $\mathrm{HbA}_{1 \mathrm{c}}$ was assessed by HPLC at the central laboratory of the university medical centre.

\section{Other measures}

Goal difficulty was assessed with one item, where participants ranked how easy or difficult it would be to reach their goal on a 9-point scale, immediately following goal assignment and at study end. A similar measure was used in previous studies ${ }^{(18)}$. Change in physical activity was assessed using the Modifiable Physical Activity Questionnaire. This questionnaire assesses leisure-time physical activities performed during the past week and was previously shown to be reliable and associated with activity and physical fitness measures ${ }^{(19)}$. Participants were asked to record the type, dose and frequency of prescribed medications by means of an interview at the assessment visits to assess possible changes in glycaemic control due to medication changes.

\section{Statistical analyses}

The distribution of outcomes was examined to assess normality and ensure that the assumptions of statistical tests were met. The Fisher exact test or the two-sample $t$ test was used to compare between-group differences in participant characteristics at baseline. Repeated measures ANOVA was used to assess outcomes. Contrast analysis was used to evaluate between-group differences in outcome measures at baseline. The time-by-group interaction effect assessed group differences in outcome changes across time. Participants were nested within groups and were treated as random effects. Intention-to-treat analysis was not performed since there were no intermediate values to carry forward from baseline. Additional analyses were conducted to examine the relationship among the change in dietary intake (i.e. change in energy, GI, GL, carbohydrate and fibre), weight and $\mathrm{HbA}_{1 \mathrm{c}}$ using Pearson's correlation coefficients. All analyses were completed using the SAS statistical software package JMP version 8.0 (SAS Institute Inc., Cary, NC, USA).

\section{Results}

A total of 209 people inquired about the study. However, twenty-five did not respond to repeated contact and thus 184 were assessed for eligibility. Of them, $108 \mathrm{did}$ not meet the inclusion criteria ( $49 \%$ of these were below the $\mathrm{HbA}_{1 \mathrm{c}}$ inclusion criterion) and thirty refused to participate. Finally, forty-six were enrolled in the study. However, of the fortysix, eleven participants discontinued before completion of the intervention and hence only thirty-five participants completed all study assessments. There were no differences in either baseline characteristics or outcomes between those who did and did not complete the study.

Table 1 reports the characteristics of participants in each treatment group. There were no significant differences between treatment groups at baseline with regard to servings consumed from food groups (Table 2), energy and nutrient intakes, weight or physiological outcomes

Table 1 Baseline demographic and diabetes characteristics of participants in each treatment group

\begin{tabular}{|c|c|c|c|c|c|}
\hline \multirow[b]{2}{*}{ Characteristic } & \multicolumn{2}{|c|}{$\begin{array}{l}\text { Six-serving group } \\
(n 15)\end{array}$} & \multicolumn{2}{|c|}{$\begin{array}{l}\text { Eight-serving group } \\
\qquad(n 20)\end{array}$} & \multirow[b]{2}{*}{$P$ value } \\
\hline & \multicolumn{2}{|c|}{$\%$} & \multicolumn{2}{|c|}{$\%$} & \\
\hline Female & \multicolumn{2}{|c|}{$60 \cdot 0$} & \multicolumn{2}{|c|}{$70 \cdot 0$} & $0 \cdot 72$ \\
\hline Caucasian & \multicolumn{2}{|c|}{$80 \cdot 0$} & \multicolumn{2}{|c|}{$95 \cdot 0$} & 0.29 \\
\hline Married & \multicolumn{2}{|c|}{$53 \cdot 5$} & \multicolumn{2}{|c|}{$70 \cdot 0$} & 0.48 \\
\hline Bachelor's degree or higher & \multirow{2}{*}{\multicolumn{2}{|c|}{$60 \cdot 0$}} & \multicolumn{2}{|c|}{$50 \cdot 0$} & $0 \cdot 73$ \\
\hline Employed full time & & & \multicolumn{2}{|c|}{$85 \cdot 0$} & $1 \cdot 00$ \\
\hline Received previous diabetes education & \multicolumn{2}{|c|}{$80 \cdot 0$} & \multicolumn{2}{|c|}{$85 \cdot 0$} & $1 \cdot 00$ \\
\hline Prescribed oral hypoglycaemic medication & \multicolumn{2}{|c|}{$80 \cdot 0$} & & & $1 \cdot 00$ \\
\hline \multirow[t]{2}{*}{ Self-monitored blood glucose } & \multicolumn{2}{|c|}{$66 \cdot 7$} & \multicolumn{2}{|c|}{$75 \cdot 0$} & $0 \cdot 71$ \\
\hline & Mean & SD & Mean & SD & \\
\hline Age (years) & $49 \cdot 60$ & $6 \cdot 67$ & $52 \cdot 55$ & $5 \cdot 94$ & $0 \cdot 19$ \\
\hline Diagnosed with diabetes (years) & $6 \cdot 40$ & $5 \cdot 18$ & $5 \cdot 80$ & $3 \cdot 61$ & $0 \cdot 70$ \\
\hline
\end{tabular}


Table 2 Within- and between-group comparisons in food group servings in adults with type 2 diabetes

\begin{tabular}{|c|c|c|c|c|c|c|c|c|c|c|c|c|}
\hline \multirow[b]{3}{*}{ Food group servings } & \multicolumn{4}{|c|}{ Baseline } & \multicolumn{5}{|c|}{ Change score } & \multirow[b]{3}{*}{$P$ value $\ddagger$} & \multirow{2}{*}{\multicolumn{2}{|c|}{$\begin{array}{c}\text { Change score } \\
\begin{array}{c}\text { All participants } \\
(n 33) \dagger\end{array}\end{array}$}} \\
\hline & \multicolumn{2}{|c|}{$\begin{array}{l}\text { Six-serving group } \\
(n 15)\end{array}$} & \multicolumn{2}{|c|}{$\begin{array}{l}\text { Eight-serving group } \\
\qquad(n \text { 20) }\end{array}$} & \multirow[b]{2}{*}{$P$ value $) \ddagger$} & \multicolumn{2}{|c|}{$\begin{array}{l}\text { Six-serving group } \\
(n 14) \dagger\end{array}$} & \multicolumn{2}{|c|}{$\begin{array}{l}\text { Eight-serving group } \\
\qquad(n \text { 19) } \dagger\end{array}$} & & & \\
\hline & Mean & SE & Mean & SE & & Mean & SE & Mean & SE & & Mean & SE \\
\hline Total servings of LGl foods & $6 \cdot 76$ & 0.94 & $6 \cdot 53$ & $0 \cdot 83$ & $0 \cdot 85$ & $1 \cdot 67^{\star}$ & $0 \cdot 82$ & $1 \cdot 88^{\star \star}$ & $0 \cdot 70$ & $0 \cdot 84$ & $1 \cdot 79^{\star \star}$ & 0.53 \\
\hline Total servings of LGl foods per $4184 \mathrm{~kJ}$ & $3 \cdot 22$ & 0.47 & $2 \cdot 90$ & $0 \cdot 41$ & $0 \cdot 61$ & $2 \cdot 05^{\star \star \star}$ & 0.47 & $1 \cdot 65^{\star \star \star}$ & $0 \cdot 40$ & 0.52 & $1 \cdot 82^{\star \star \star}$ & $0 \cdot 30$ \\
\hline Fruit (servings/4184 kJ) & 0.49 & $0 \cdot 18$ & 0.58 & $0 \cdot 16$ & $0 \cdot 71$ & $0 \cdot 62^{\star \star}$ & 0.23 & $0 \cdot 47^{*}$ & $0 \cdot 20$ & $0 \cdot 64$ & $0.53^{\star \star \star}$ & $0 \cdot 15$ \\
\hline Fruit juice (100\% juice and frozen concentrate) & $0 \cdot 13$ & 0.05 & $0 \cdot 12$ & 0.04 & $0 \cdot 90$ & -0.06 & 0.07 & -0.01 & 0.06 & 0.62 & -0.03 & 0.04 \\
\hline Whole fruit (fresh, frozen, cooked/canned, dried)§ & $0 \cdot 36$ & $0 \cdot 17$ & 0.45 & $0 \cdot 15$ & $0 \cdot 67$ & $0 \cdot 67^{\star \star}$ & $0 \cdot 21$ & $0 \cdot 49^{\star \star}$ & $0 \cdot 18$ & 0.51 & $0 \cdot 57^{\star \star \star}$ & $0 \cdot 13$ \\
\hline Vegetables (servings/4184 kJ) & $2 \cdot 04$ & $0 \cdot 28$ & 1.46 & $0 \cdot 24$ & $0 \cdot 12$ & $0 \cdot 14$ & $0 \cdot 32$ & $0 \cdot 58^{*}$ & $0 \cdot 28$ & $0 \cdot 32$ & 0.39 & $0 \cdot 21$ \\
\hline Green/yellow vegetables (e.g. broccoli, carrots, sweet potato)§ & $0 \cdot 41$ & $0 \cdot 12$ & $0 \cdot 37$ & $0 \cdot 10$ & $0 \cdot 81$ & $0 \cdot 32^{*}$ & $0 \cdot 15$ & $0 \cdot 30^{*}$ & $0 \cdot 13$ & $0 \cdot 89$ & $0 \cdot 31^{\star *}$ & $0 \cdot 10$ \\
\hline Tomatoes (raw, sauce, paste, salsa) § & $0 \cdot 30$ & 0.06 & $0 \cdot 20$ & 0.05 & $0 \cdot 20$ & -0.03 & 0.09 & 0.07 & 0.07 & $0 \cdot 40$ & 0.03 & 0.06 \\
\hline Potatoes (all white, including fried) & 0.33 & 0.06 & $0 \cdot 22$ & 0.05 & $0 \cdot 16$ & $-0 \cdot 24^{\star *}$ & 0.08 & -0.06 & 0.07 & 0.09 & $-0 \cdot 13^{*}$ & 0.05 \\
\hline Legumes (cooked, dried beans)§ & 0.07 & 0.05 & 0.09 & $0 \cdot 04$ & $0 \cdot 85$ & $0 \cdot 10$ & 0.06 & 0.03 & 0.05 & $0 \cdot 34$ & 0.06 & 0.04 \\
\hline Other vegetables (e.g. corn, peas, cabbage, squash)§ & $0 \cdot 76$ & $0 \cdot 13$ & 0.58 & $0 \cdot 12$ & $0 \cdot 31$ & -0.03 & $0 \cdot 19$ & $0 \cdot 17$ & $0 \cdot 17$ & 0.45 & 0.09 & $0 \cdot 13$ \\
\hline Vegetable juice $§$ & $0 \cdot 17$ & 0.08 & $0 \cdot 00$ & 0.07 & $0 \cdot 14$ & 0.00 & 0.04 & 0.06 & 0.04 & $0 \cdot 30$ & 0.03 & 0.03 \\
\hline Meat, fish, poultry (servings/4184 kJ) & $3 \cdot 31$ & 0.40 & $3 \cdot 37$ & 0.35 & 0.91 & 0.27 & 0.38 & $0 \cdot 14$ & $0 \cdot 33$ & $0 \cdot 81$ & $0 \cdot 19$ & $0 \cdot 25$ \\
\hline Meat, fish, poultry, regular fat & 1.59 & 0.24 & $1 \cdot 74$ & $0 \cdot 21$ & $0 \cdot 64$ & $-0 \cdot 19$ & $0 \cdot 28$ & $-0 \cdot 40$ & 0.24 & 0.58 & -0.31 & $0 \cdot 18$ \\
\hline Meat, fish, poultry, lean & 1.06 & $0 \cdot 26$ & $0 \cdot 88$ & $0 \cdot 22$ & 0.59 & $0 \cdot 15$ & $0 \cdot 24$ & 0.04 & $0 \cdot 21$ & $0 \cdot 74$ & 0.09 & $0 \cdot 16$ \\
\hline Eggs & 0.29 & 0.09 & $0 \cdot 30$ & 0.07 & $0 \cdot 96$ & -0.07 & 0.07 & 0.07 & 0.07 & $0 \cdot 19$ & $0 \cdot 01$ & 0.05 \\
\hline Nuts, seeds, butter§ & $0 \cdot 37$ & $0 \cdot 27$ & 0.45 & 0.23 & $0 \cdot 81$ & 0.38 & $0 \cdot 20$ & $0 \cdot 42^{*}$ & $0 \cdot 17$ & $0 \cdot 90$ & $0 \cdot 40^{\star *}$ & $0 \cdot 13$ \\
\hline Grains (servings/4184 kJ) & $2 \cdot 57$ & $0 \cdot 26$ & $2 \cdot 69$ & $0 \cdot 22$ & $0 \cdot 74$ & 0.09 & $0 \cdot 28$ & -0.03 & $0 \cdot 24$ & $0 \cdot 73$ & 0.02 & $0 \cdot 17$ \\
\hline Wholegrain flour and dry mixes & 0.09 & 0.08 & $0 \cdot 14$ & 0.07 & 0.64 & 0.07 & 0.09 & $0 \cdot 20^{\star \star}$ & 0.08 & $0 \cdot 27$ & $0 \cdot 14^{*}$ & 0.06 \\
\hline Partial wholegrain flour and dry mixes & 0.00 & $0 \cdot 01$ & $0 \cdot 00$ & 0.01 & $0 \cdot 80$ & 0.01 & 0.01 & 0.01 & $0 \cdot 01$ & 0.96 & 0.01 & 0.01 \\
\hline Refined grain flour and dry mixes & $0 \cdot 75$ & $0 \cdot 17$ & 0.59 & $0 \cdot 15$ & 0.48 & $-0 \cdot 11$ & $0 \cdot 26$ & 0.04 & 0.22 & 0.66 & -0.03 & $0 \cdot 17$ \\
\hline Wholegrain breads & $0 \cdot 13$ & 0.06 & 0.09 & 0.05 & 0.63 & 0.05 & 0.08 & $0 \cdot 11$ & 0.07 & $0 \cdot 60$ & 0.08 & 0.05 \\
\hline Partial wholegrain breads & $0 \cdot 11$ & $0 \cdot 14$ & $0 \cdot 30$ & $0 \cdot 12$ & $0 \cdot 32$ & 0.32 & $0 \cdot 19$ & 0.24 & $0 \cdot 16$ & $0 \cdot 74$ & $0 \cdot 28^{*}$ & $0 \cdot 12$ \\
\hline Refined grain breads & $1 \cdot 22$ & $0 \cdot 16$ & $1 \cdot 20$ & $0 \cdot 14$ & 0.93 & -0.38 & $0 \cdot 19$ & $-0 \cdot 66^{\star \star \star}$ & $0 \cdot 17$ & $0 \cdot 27$ & $-0 \cdot 54^{\star \star \star}$ & $0 \cdot 12$ \\
\hline Wholegrain cereals & $0 \cdot 10$ & 0.04 & $0 \cdot 14$ & 0.04 & 0.55 & -0.04 & 0.04 & -0.02 & 0.04 & $0 \cdot 76$ & -0.03 & 0.03 \\
\hline Wholegrain pasta§ & 0.00 & 0.03 & $0 \cdot 01$ & 0.03 & $0 \cdot 77$ & $0 \cdot 10$ & 0.05 & 0.03 & 0.04 & $0 \cdot 32$ & 0.06 & 0.03 \\
\hline Dairy (servings/4184 kJ) & $0 \cdot 82$ & $0 \cdot 17$ & $0 \cdot 79$ & $0 \cdot 15$ & $0 \cdot 87$ & $0.53^{\star \star \star}$ & $0 \cdot 12$ & $0 \cdot 11$ & $0 \cdot 10$ & 0.01 & $0 \cdot 29^{\star \star}$ & 0.09 \\
\hline Milk, cheese, yoghurt, full fat $\S$ & 0.28 & 0.07 & 0.35 & 0.06 & $0 \cdot 41$ & -0.05 & 0.06 & $-0 \cdot 11^{*}$ & 0.05 & 0.46 & $-0.09^{*}$ & 0.04 \\
\hline Milk, cheese, yoghurt, reduced fat $\S$ & 0.25 & $0 \cdot 08$ & $0 \cdot 19$ & 0.07 & $0 \cdot 62$ & $0 \cdot 30^{\star \star}$ & $0 \cdot 10$ & $0 \cdot 17$ & 0.09 & $0 \cdot 35$ & $0 \cdot 22^{\star \star}$ & 0.07 \\
\hline Milk, cheese, yoghurt, non-fat§ & $0 \cdot 26$ & $0 \cdot 16$ & $0 \cdot 18$ & $0 \cdot 14$ & $0 \cdot 71$ & $0 \cdot 20^{*}$ & 0.08 & 0.00 & 0.07 & 0.06 & 0.08 & 0.05 \\
\hline Fats (servings $/ 4184 \mathrm{~kJ}$ ) & $2 \cdot 31$ & $0 \cdot 26$ & 1.91 & $0 \cdot 23$ & $0 \cdot 26$ & $-0.77^{\star}$ & $0 \cdot 31$ & $-0 \cdot 14$ & $0 \cdot 27$ & $0 \cdot 13$ & $-0 \cdot 41^{*}$ & $0 \cdot 21$ \\
\hline Animal fat (butter, shortening, cream) & $0 \cdot 75$ & $0 \cdot 16$ & 0.50 & $0 \cdot 14$ & $0 \cdot 24$ & $-0 \cdot 39^{\star}$ & $0 \cdot 17$ & $-0 \cdot 11$ & $0 \cdot 15$ & $0 \cdot 23$ & $-0 \cdot 23^{*}$ & $0 \cdot 11$ \\
\hline Vegetable fat (margarine, oil, salad dressing) & 1.55 & $0 \cdot 20$ & $1 \cdot 41$ & $0 \cdot 17$ & $0 \cdot 60$ & -0.38 & $0 \cdot 26$ & -0.04 & $0 \cdot 22$ & 0.33 & $-0 \cdot 18$ & $0 \cdot 17$ \\
\hline
\end{tabular}

LGI, low glycaemic index.

Significant within-group change from baseline using contrasts based on repeated measures ANOVA $\left({ }^{\star} P \leq 0.05,{ }^{* *} P \leq 0 \cdot 01,{ }^{* * *} P \leq 0.001\right)$.

One participant in each treatment group reported low energy intake at study end due to illness and was deleted from the analysis.

SIncluded in summation of total servings of LGI foods. 
(Table 3). Physical activity and prescribed medications were similar between groups throughout the study and did not change significantly.

Immediately following goal assignment, no significant differences were observed between groups in rating goal difficulty. However, difficulty ratings for the eight-serving LGI group $($ mean $=3.40(\operatorname{se~} 0.50))$ were higher than those for the six-serving LGI group $($ mean $=2 \cdot 27(\operatorname{se} 0 \cdot 57))$ following goal assignment, but this was not statistically significant $(P=0 \cdot 14)$. At study end, participants in the eight-serving LGI group $($ mean $=3.80($ SE 0.50) $)$ perceived their goal to be significantly more difficult than participants in the six-serving LGI group (mean $=1.33$ (SE 0.57); $P=0 \cdot 002$ ).

There was no significant difference between groups with regard to the change in servings of LGI foods (Table 2). For all participants combined, consumption of LGI foods increased by a mean of 1.79 (SE 0.53) servings daily. Both treatment groups reported a significant increase in servings of whole fruits and green/yellow vegetables, with no significant difference between groups. For all participants combined, there were significant increases in servings of nuts, seeds and butter, wholegrain flour and dry mixes, as well as in partial wholegrain breads, and significant decreases in servings of potatoes, refined grain breads and animal fats. The six-serving LGI group had a significantly greater increase in mean servings of dairy foods than the eight-serving LGI group. Correspondingly, the six-serving LGI group had a significantly greater increase in $\mathrm{Ca}$ and vitamin $\mathrm{D}$ intakes than the eightserving LGI group (Table 3). Both treatment groups had significant decreases in mean energy and carbohydrate intakes, GI and GL and a significant increase in fibre intake. Participants as a whole had significant reductions in total fat, saturated fat and added sugars and a significant increase in protein intake.

No significant differences were observed between groups with regard to weight or $\mathrm{HbA}_{1 \mathrm{c}}$ at baseline or study end (Table 3). However, there was a significant reduction in mean $\mathrm{HbA}_{1 \mathrm{c}}(-0.58$ (sE 0.21$\left.) \% ; P=0 \cdot 01\right)$ and weight $(-2.3(\mathrm{se} 0 \cdot 78) \mathrm{kg} ; P=0 \cdot 01)$ among all participants combined. When changes in weight-related outcomes were examined by gender, there was a significant reduction in weight outcomes among all men combined, and women in the six-serving LGI group had significant reductions in weight and BMI.

Correlation analyses among changes in energy, GI, GL, carbohydrate, fibre, weight and $\mathrm{HbA}_{1 \mathrm{c}}$ revealed no significant relationship between change in weight and change in $\mathrm{HbA}_{1 \mathrm{c}}(r=0.07 ; P=0 \cdot 71)$. None of the dietary parameters were significantly related to change in $\mathrm{HbA}_{1 \mathrm{c}}$. The relationship between change in weight and change in consumption of LGI foods per $4184 \mathrm{~kJ}$ was $r=-0 \cdot 32$ $(P=0 \cdot 08)$, and the relationship between change in weight and change in percentage energy from fibre was $r=-0 \cdot 34(P=0 \cdot 06)$.

\section{Discussion}

To the best of our knowledge, the present study is the first of this kind to examine the effect of goal difficulty on dietary outcomes, weight status and glycaemic control. There were no significant differences between goal difficulty groups in consumption of LGI foods at study end. However, the intervention was effective in promotng behavioural change. Participants increased consumption of LGI foods by almost two servings daily. Although participants in the six-serving LGI group were consuming slightly more than six servings of LGI foods daily at baseline, they increased consumption at study end. Participants in the eight-serving LGI group achieved the goal of consuming eight servings of LGI foods daily. Furthermore, mean dietary GI approached 55 as anticipated, a level associated with reduced disease risk ${ }^{(6)}$. Participants in the eight-serving LGI group perceived their goal to be significantly more difficult by the end of the study after attempting to achieve their goal.

At baseline, participants did not receive an individual goal regarding LGI foods based on their energy needs or food patterns and were not informed of the number of servings consumed. Information on an effective, incremental goal with regard to servings of LGI foods was unavailable at study initiation. The six- and eight-serving goals were estimated on the basis of dietary patterns (not servings consumed) from previous intervention and feeding studies on $\mathrm{GI}^{(10,20,21)}$ and sample menus created a priori. A reasonable level of difficulty was estimated to be six to eight servings daily for a free-living sample. These recommendations are consistent with those in a recent study in which six servings of LGI foods daily for a $6276 \mathrm{~kJ}$ $(1500 \mathrm{kcal})$ diet, eight servings for a $8368 \mathrm{~kJ}(2000 \mathrm{kcal})$ diet and ten servings for a $10460 \mathrm{~kJ}(2500 \mathrm{kcal})$ diet were prescribed $^{(22)}$. Mean energy intake in the present study exceeded $8368 \mathrm{~kJ} / \mathrm{d}$ at baseline and the mean BMI values of participants were in the obese category. Thus, a reduction in energy intake would be recommended to improve health outcomes ${ }^{(1)}$, and the assigned goals were within the target range for weight loss. Participants in the present study decreased energy intake and still consumed almost two additional servings of LGI foods daily. Therefore, a reasonable individual goal would be to substitute two additional servings of LGI foods daily for higher GI foods while also reducing energy intake to promote weight loss. These findings inform future studies regarding the magnitude of change in GI that can be expected following a behavioural intervention. Further research is needed to determine whether providing an individualized goal would be more effective in promoting behavioural change than providing a generic goal.

All participants in the present study were given specific goals regarding the number of LGI foods to consume; therefore, it was not possible to assess the independent contribution to study outcomes of having a specific goal 
Table 3 Within- and between-group comparisons in nutrient intakes, weight outcomes and $\mathrm{HbA}_{1 \mathrm{c}}$ in adults with type 2 diabetes

\begin{tabular}{|c|c|c|c|c|c|c|c|c|c|c|c|c|}
\hline \multirow[b]{3}{*}{ Outcome } & \multicolumn{4}{|c|}{ Baseline } & \multicolumn{5}{|c|}{ Change score } & & \multirow{2}{*}{\multicolumn{2}{|c|}{$\begin{array}{c}\text { Change score } \\
\text { All participants }(n \text { 35)† }\end{array}$}} \\
\hline & \multicolumn{2}{|c|}{ Six-serving group ( $n$ 15) } & \multicolumn{2}{|c|}{ Eight-serving group ( $n$ 20) } & \multirow[b]{2}{*}{$P$ value $\ddagger$} & \multicolumn{2}{|c|}{ Six-serving group $(n$ 15) +} & \multicolumn{3}{|c|}{ Eight-serving group $(n 20)+$} & & \\
\hline & Mean & SE & Mean & SE & & Mean & SE & Mean & SE & $P$ value $\ddagger$ & Mean & SE \\
\hline Energy (kJ) & $9082 \cdot 2$ & $579 \cdot 9$ & $9520 \cdot 7$ & $502 \cdot 5$ & 0.57 & $-2111 \cdot 7^{\star \star \star}$ & $554 \cdot 4$ & $-1876 \cdot 1^{\star \star \star}$ & $476 \cdot 6$ & $0 \cdot 75$ & $-1976 \cdot 9^{\star \star \star}$ & $356 \cdot 3$ \\
\hline Energy (kcal) & $2170 \cdot 7$ & $138 \cdot 6$ & $2275 \cdot 5$ & $120 \cdot 1$ & 0.57 & $-504 \cdot 7^{\star \star \star}$ & $132 \cdot 5$ & $-448 \cdot 4^{\star \star \star}$ & $113 \cdot 9$ & $0 \cdot 75$ & $-472 \cdot 49^{\star * \star}$ & $85 \cdot 15$ \\
\hline Carbohydrate (g) & $226 \cdot 70$ & $17 \cdot 20$ & $250 \cdot 19$ & $14 \cdot 90$ & $0 \cdot 31$ & $-40 \cdot 35^{\star}$ & $17 \cdot 26$ & $-46 \cdot 80^{\star *}$ & $14 \cdot 85$ & $0 \cdot 78$ & $-44 \cdot 08^{\star \star \star}$ & $11 \cdot 09$ \\
\hline Carbohydrate (\%E) & $41 \cdot 35$ & 1.95 & $42 \cdot 55$ & $1 \cdot 69$ & 0.64 & 3.63 & $2 \cdot 33$ & $1 \cdot 07$ & $2 \cdot 01$ & $0 \cdot 41$ & $2 \cdot 16$ & $1 \cdot 52$ \\
\hline Protein (\%E) & $17 \cdot 63$ & $1 \cdot 18$ & $17 \cdot 64$ & $1 \cdot 03$ & 0.99 & $3 \cdot 10^{\star \star}$ & $1 \cdot 02$ & 0.68 & $0 \cdot 88$ & 0.08 & $1 \cdot 71^{*}$ & 0.68 \\
\hline Total fat (\%E) & $40 \cdot 85$ & $1 \cdot 74$ & $39 \cdot 58$ & $1 \cdot 51$ & 0.58 & $-6 \cdot 58^{\star \star}$ & $2 \cdot 25$ & $-1 \cdot 58$ & 1.93 & $0 \cdot 10$ & $-3 \cdot 69^{*}$ & $1 \cdot 52$ \\
\hline Saturated fat $(\% \mathrm{E})$ & $13 \cdot 73$ & 0.65 & $13 \cdot 41$ & 0.56 & $0 \cdot 71$ & $-2 \cdot 36^{\star *}$ & $0 \cdot 76$ & $-1 \cdot 26$ & 0.66 & 0.28 & $-1 \cdot 73^{\star *}$ & 0.50 \\
\hline Cholesterol (mg/4184 kJ) & $170 \cdot 88$ & $20 \cdot 15$ & $167 \cdot 57$ & $17 \cdot 45$ & 0.90 & $-31 \cdot 09$ & $19 \cdot 48$ & $-4 \cdot 33$ & $16 \cdot 75$ & $0 \cdot 31$ & $-15 \cdot 71$ & $12 \cdot 82$ \\
\hline Total fibre $(\mathrm{g} / 4184 \mathrm{~kJ})$ & $10 \cdot 16$ & 0.88 & $9 \cdot 65$ & 0.77 & 0.66 & $2 \cdot 53^{\star \star}$ & 0.79 & $3 \cdot 79^{\star \star *}$ & 0.68 & 0.24 & $3 \cdot 25^{\star \star \star}$ & 0.51 \\
\hline Insoluble fibre (g/4184kJ) & $6 \cdot 92$ & 0.67 & $6 \cdot 36$ & 0.58 & 0.53 & $1 \cdot 95^{\star \star}$ & 0.65 & $3 \cdot 01^{* \star *}$ & 0.56 & 0.23 & $2 \cdot 56^{\star \star \star}$ & 0.42 \\
\hline Soluble fibre $(\mathrm{g} / 4184 \mathrm{~kJ})$ & $3 \cdot 16$ & 0.34 & $3 \cdot 20$ & $0 \cdot 30$ & 0.92 & 0.52 & 0.35 & $0 \cdot 77^{\star}$ & $0 \cdot 30$ & 0.58 & $0 \cdot 67^{\star \star}$ & 0.23 \\
\hline Total sugars (g/4184 kJ) & 36.95 & $3 \cdot 78$ & $43 \cdot 01$ & $3 \cdot 28$ & 0.23 & $10 \cdot 26^{\star \star}$ & 3.53 & $2 \cdot 94$ & 3.04 & $0 \cdot 13$ & $6 \cdot 05^{\star}$ & $2 \cdot 36$ \\
\hline Added sugars (g/4184 kJ) & $19 \cdot 53$ & $3 \cdot 12$ & $27 \cdot 53$ & $2 \cdot 70$ & 0.06 & $-5 \cdot 13$ & $2 \cdot 71$ & $-6 \cdot 38^{\star \star}$ & $2 \cdot 33$ & $0 \cdot 73$ & $-5 \cdot 85^{\star \star}$ & $1 \cdot 75$ \\
\hline $\mathrm{Ca}(\mathrm{mg} / 4184 \mathrm{~kJ})$ & $467 \cdot 72$ & $51 \cdot 93$ & $420 \cdot 41$ & $44 \cdot 98$ & 0.49 & $154 \cdot 11^{\star \star \star}$ & $41 \cdot 19$ & $43 \cdot 20$ & $35 \cdot 39$ & 0.05 & $89 \cdot 83^{\star \star}$ & $28 \cdot 48$ \\
\hline Vitamin D ( $\mu \mathrm{g} / 4184 \mathrm{~kJ})$ & 2.09 & 0.46 & $2 \cdot 23$ & 0.40 & 0.82 & $1 \cdot 01^{* *}$ & 0.34 & $-0 \cdot 12$ & 0.29 & 0.02 & 0.36 & 0.24 \\
\hline Glycaemic index & $61 \cdot 66$ & $1 \cdot 12$ & $61 \cdot 11$ & 0.97 & $0 \cdot 71$ & $-6 \cdot 62^{\star \star \star}$ & $1 \cdot 31$ & $-4 \cdot 61^{\star \star \star}$ & $1 \cdot 13$ & 0.25 & $-5 \cdot 46^{\star \star \star}$ & $0 \cdot 86$ \\
\hline Glycaemic load & $127 \cdot 83$ & $10 \cdot 02$ & $139 \cdot 45$ & $8 \cdot 68$ & $0 \cdot 38$ & $-36 \cdot 12^{\star \star \star}$ & $9 \cdot 83$ & $-36 \cdot 82^{\star \star \star}$ & $8 \cdot 45$ & 0.96 & $-36 \cdot 54^{\star \star \star}$ & $6 \cdot 30$ \\
\hline \multicolumn{13}{|l|}{ Weight (kg) } \\
\hline Male & $122 \cdot 73$ & $10 \cdot 11$ & $106 \cdot 68$ & $10 \cdot 11$ & 0.29 & $-2 \cdot 51$ & $1 \cdot 27$ & $-2 \cdot 47$ & $1 \cdot 27$ & 0.98 & $-2 \cdot 49^{\star \star}$ & 0.86 \\
\hline Female & $110 \cdot 84$ & $6 \cdot 33$ & $100 \cdot 73$ & $5 \cdot 27$ & 0.23 & $-3 \cdot 96^{*}$ & $1 \cdot 74$ & -0.99 & $1 \cdot 45$ & $0 \cdot 21$ & $-2 \cdot 20$ & $1 \cdot 13$ \\
\hline \multicolumn{13}{|l|}{ Waist circumference (cm) } \\
\hline Male & $128 \cdot 40$ & $6 \cdot 58$ & $115 \cdot 62$ & 6.58 & $0 \cdot 20$ & $-2 \cdot 52$ & $1 \cdot 25$ & $-2 \cdot 84^{*}$ & $1 \cdot 25$ & 0.86 & $-2 \cdot 68^{\star \star}$ & 0.85 \\
\hline \multirow{2}{*}{\multicolumn{13}{|c|}{ BMI $\left(\mathrm{kg} / \mathrm{m}^{2}\right)$}} \\
\hline & & & & & & & & & & & & \\
\hline Male & $39 \cdot 32$ & $2 \cdot 56$ & $32 \cdot 53$ & $2 \cdot 56$ & 0.09 & $-0 \cdot 82$ & 0.41 & $-0 \cdot 76$ & 0.41 & 0.92 & $-0 \cdot 79^{*}$ & $0 \cdot 27$ \\
\hline Female & $40 \cdot 34$ & $2 \cdot 27$ & 38.09 & $1 \cdot 89$ & 0.45 & $-1 \cdot 44^{*}$ & 0.65 & $-0 \cdot 37$ & 0.54 & 0.23 & $-0 \cdot 81$ & 0.42 \\
\hline $\mathrm{HbA}_{1 \mathrm{c}}(\%)$ & $8 \cdot 84$ & 0.46 & $8 \cdot 86$ & $0 \cdot 40$ & 0.98 & -0.38 & 0.33 & $-0 \cdot 73^{\star \star}$ & $0 \cdot 28$ & $0 \cdot 43$ & $-0 \cdot 58^{\star *}$ & $0 \cdot 21$ \\
\hline
\end{tabular}

$\mathrm{HbA}_{1 \mathrm{c}}$, glycosylated $\mathrm{Hb}$; \% $\mathrm{E}$, percentage of energy.

trasts based on repeated measures ANOVA $\left({ }^{*} P \leq 0.05,{ }^{* *} P \leq 0.01{ }^{* * *} P \leq 0.001\right)$

fBetween-group comparison at each assessment using contrasts based on repeated measures ANOVA. 
compared with a vague or 'do your best' goal. However, the mean decrease in GI in the present study $(-5 \cdot 46)$ was greater than the mean decrease in GI in a previous study $(-2 \cdot 1$ to $-2 \cdot 8)$ in which the GI information provided during the intervention was similar to that in the present study and participants were encouraged to substitute lower for higher GI foods but without a specific goal regarding the number of LGI foods to consume ${ }^{(8)}$. Taken together, the findings of these studies support the need to set specific goals, rather than 'do your best' goals, to facilitate dietary behavioural change. Specific dietary goals could be established for the recommended daily number of servings or grams depending on the food group(s) or nutrient targeted. A specific goal that is too easy may be more effective in facilitating behavioural change than an easy but vague 'do your best' goal.

Little has been reported regarding food consumption patterns and dietary quality in adults with type 2 diabetes. Prior research found that few adults with type 2 diabetes met the food and nutrient intake recommendations in dietary guidelines ${ }^{(23)}$. The percentage of energy from saturated fat at baseline in both treatment groups in the present study exceeded the recommended intake of $<7 \%$ of energy for people with diabetes ${ }^{(1)}$. Participants in the present study did not meet the recommendation for saturated fat at study end. However, the percentage of energy from total and saturated fat declined significantly following the intervention. People with diabetes are also encouraged to consume a variety of fibre-containing foods ${ }^{(1)}$, and fibre intake increased significantly in the present study. Consumption of dairy foods increased, which contributed to the increased consumption of $\mathrm{Ca}$. Intakes of added sugars declined. Although dietary goals were not fully achieved, fat, fibre, Ca and added sugar intakes improved, indicating that a lower GI diet can improve dietary quality and better meet public health recommendations for dietary intake ${ }^{(24)}$.

In addition, the change in food choices was made by selecting foods that were readily available in restaurants and supermarkets; speciality foods were not provided in the present study. Prior research found that small incremental changes from readily available foods can help people meet dietary guidelines ${ }^{(25)}$. Patients can make small dietary changes that over time progressively improve their diet and reduce risk for chronic disease.

For all participants combined, modest weight loss occurred during the present short-term study. The mean weight loss achieved in the present study $(-2 \cdot 3 \mathrm{~kg})$ was greater than the mean weight loss in two studies with a similar intervention focus but without specific goals for consumption of LGI foods; one ${ }^{(9)}$ reported a mean weight loss of $-1 \cdot 1 \mathrm{~kg}(P<0 \cdot 01)$ and a second ${ }^{(11)}$ reported a mean weight loss of $-1.5 \mathrm{~kg}(P=0 \cdot 06)$. Participants in a third study were given a specific goal for LGI foods (consume at least half of their daily carbohydrate from LGI foods) and lost an average of $-2 \cdot 2 \mathrm{~kg}$ at 3 -month follow-up ${ }^{(26)}$, an outcome similar to that achieved in the present study. Thus, an energy-restricted diet with specific LGI goals can facilitate modest weight loss in adults with diabetes.

Not only were modest improvements in weight control achieved in the present study, but glycaemic control also improved. The change in $\mathrm{HbA}_{1 \mathrm{c}}(-0.58 \%)$ is slightly greater than the approximately $0 \cdot 4 \%$ reduction in $\mathrm{HbA}_{1 \mathrm{c}}$ found in a meta-analysis after an average duration of 10 weeks on an LGI $\operatorname{diet}^{(4)}$. The US Food and Drug Administration recognizes a $0 \cdot 3-0 \cdot 4 \%$ reduction in $\mathrm{HbA}_{1 \mathrm{c}}$ as clinically meaningful in the evaluation of drugs for diabetes management ${ }^{(22,27)}$. Reductions in $\mathrm{HbA}_{1 \mathrm{c}}$ are associated with reduced risk for the microvascular and macrovascular complications associated with type 2 diabetes ${ }^{(28-30)}$. In a recent trial, a $0.67 \%$ reduction in $\mathrm{HbA}_{1 \mathrm{c}}$ resulted in a one-fifth reduction in the development of new or worsening nephropathy ${ }^{(31)}$. Thus, improved glycaemic control of the magnitude observed in the present study has important public health implications for reducing the morbidity associated with diabetes.

The present study has a few limitations. First, the sample size was small for the present initial study and the sample consisted primarily of white individuals, many of whom had a college education. The generalizability of these findings among a larger and more diverse sample is unknown and should be determined in future studies. Second, with the observed sample size and SD, we could detect a mean difference of two servings per $4184 \mathrm{~kJ}$ with $80 \%$ power $(\alpha=0.05)$ in the change of LGI foods. These findings inform the sample size needed for future studies to detect a difference in change between control and treatment groups. Third, no control group was used in the present study because the purpose of the study was to evaluate the effect of two dietary goals on the adoption of a lower GI diet. Prior research found no significant decrease in dietary GI among participants in the control group $^{(8)}$. Finally, the GI value of some foods has not been laboratory tested and GI values were estimated on the basis of the nutrient composition and/or GI value of similar foods in the NDS-R database. The methodology for selecting GI values in NDS-R is similar to that reported in previous research ${ }^{(32)}$.

\section{Conclusion}

A specific goal to consume six to eight servings of LGI foods daily, in conjunction with a behavioural nutritional intervention, can improve dietary GI, GL, food choices, body weight and $\mathrm{HbA}_{1 \mathrm{c}}$ in adults with type 2 diabetes. Findings suggest that clinicians and educators should counsel patients to help them set specific behavioural targets and identify strategies for achieving those targets. Setting a specific goal for the consumption of LGI foods may be beneficial for those who have used other meal 
planning methods, such as carbohydrate counting, with limited success or those who have waned from the prescribed meal planning approach and need to refocus their efforts. In addition, patients with persistent postprandial hyperglycaemia may benefit from a lower GI diet. Small incremental changes in food choices can improve dietary quality and an energy-restricted lower GI diet can promote modest short-term weight loss and improvement in glycaemic control. Determining whether an individualized approach to goal setting or the setting of more difficult goals results in greater reduction in GI or improvements in dietary quality requires further research. Additional research is needed to identify effective goalsetting strategies for maintenance of dietary change.

\section{Acknowledgements}

The project described was supported by Award no. UL1RR025755 from the National Center for Research Resources. The content is solely the responsibility of the authors and does not necessarily represent the official views of the National Center for Research Resources or the National Institutes of Health. The authors have no conflict of interest to declare. C.K.M. and A.H. designed the study, developed the intervention, implemented the study and interpreted the results; M.P. and H.N. assisted with study design, data analyses and interpretation. The study participants are deeply appreciated for their time and participation.

\section{References}

1. American Diabetes Association (2008) Nutrition recommendations and interventions for diabetes: a position statement of the American Diabetes Association. Diabetes Care 31, Suppl. 1, S61-S78.

2. Gutschall MD, Miller CK, Mitchell DC et al. (2009) A randomized behavioural trial targeting glycaemic index improves dietary, weight and metabolic outcomes in patients with type 2 diabetes. Public Health Nutr 12, 1846-1854.

3. Anderson JW, Randles KM, Kendall CWC et al. (2004) Carbohydrate and fiber recommendations for individuals with diabetes: a quantitative assessment and meta-analysis of the evidence. J Am Coll Nutr 23, 5-17.

4. Brand-Miller J, Hayne S, Petocz P et al. (2003) Lowglycemic index diets in the management of diabetes: a meta-analysis of randomized controlled trials. Diabetes Care 26, 2261-2267.

5. DeWalt DA, Davis TC, Wallace AS et al. (2009) Goal setting in diabetes self-management: taking the baby steps to success. Patient Educ Counsel 77, 218-223.

6. Locke EA \& Latham GP (1990) A Theory of Goal Setting and Task Performance. Englewood Cliffs, NJ: Prentice Hall, Inc.

7. Barclay AW, Petocz P, McMillan-Price J et al. (2008) Glyemic index, glycemic load, and chronic disease risk - a metaanalysis of observational studies. Am J Clin Nutr 87, 627-637.

8. Miller CK, Gutschall MD \& Mitchell DC (2009) Change in food choices following a glycemic load intervention in adults with type 2 diabetes. J Am Diet Assoc 109, 319-324.
9. Cheong SH, McCargar LJ, Paty BW et al. (2009) The First Step First Bite Program: guidance to increase physical activity and daily intake of low-glycemic index foods. $J \mathrm{Am}$ Diet Assoc 109, 1411-1416.

10. Brand JC, Colagiuri S, Crossman S et al. (1991) Lowglycemic index foods improve long-term glycemic control in NIDDM. Diabetes Care 14, 95-101.

11. Jimenez-Cruz A, Bacardi-Gascon M, Turnbull WH et al. (2003) A flexible, low-glycemic index Mexican-style diet in overweight and obese subjects with type 2 diabetes improves metabolic parameters during a 6-week treatment period. Diabetes Care 26, 1967-1970.

12. Nooyens ACJ, Baan CA, Spijkerman AMW et al. (2010) Type 2 diabetes and cognitive decline in middle-aged men and women: the Doetinchem Cohort Study. Diabetes Care 33, 1964-1969.

13. Folstein MF, Folstein SE \& McHugh PR (1975) Mini-mental state: a practical method for grading the cognitive state of patients for the clinician. J Psychiatr Res 12, 189-198.

14. United States Food and Drug Administration (2005) Code of Federal Regulations: Title 21: Food and Drugs: Part 101Food Labeling - 101.12. Reference amounts customarily consumed per eating occasion. http://cfr.vlex.com/vid/ customarily-consumed-eating-occasion-19705320 (accessed May 2010).

15. Atkinson FS, Foster-Powell K \& Brand-Miller JC (2008) International tables of glycemic index and glycemic load values: 2008. Diabetes Care 31, 2281-2283.

16. Brand-Miller JC, Wolever TMS, Foster-Powell K et al. (2003) The New Glucose Revolution. New York: Marlowe and Company.

17. Centers for Disease Control and Prevention (2007) National Health and Nutrition Examination Survey (NHANES) Anthropometry Procedures Manual. Atlanta, GA: CDC; available at http://cdc.gov/nchs/data/nhanes/ nhanes_07_08/manual_an.pdf

18. Latham GP, Mitchell TR \& Dossett DL (1978) Importance of participative goal setting and anticipated rewards on goal difficulty and job performance. J Appl Psychol 63, $163-171$.

19. Gabriel KP, McClain JJ, Lee CD et al. (2009) Evaluation of physical activity measures used in middle-aged women. Med Sci Sports Exerc 41, 1403-1412.

20. Frost G, Wilding J \& Beecham J (1994) Dietary advice based on the glycaemic index improves dietary profile and metabolic control in type 2 diabetic patients. Diabet Med 11, 397-401.

21. Wolever TMS, Jenkins DJA, Vuksan V et al. (1992) Beneficial effect of a low glycaemic index diet in type 2 diabetes. Diabet Med 9, 451-458.

22. Jenkins DJA, Kendall CWC, McKeown-Eyssen G et al. (2008) Effect of a low-glycemic index or a high-cereal fiber diet on type 2 diabetes: a randomized trial. JAMA 300, 2742-2753.

23. Vitolins MZ, Anderson AM, Delahanty L et al. (2009) Action for Health in Diabetes (Look AHEAD) trial: baseline evaluation of selected nutrients and food group intake. J Am Diet Assoc 109, 1367-1375.

24. United States Department of Health and Human Services and United States Department of Agriculture (2005) Dietary Guidelines for Americans, 2005, 6th ed. Washington, DC: US Government Printing Office.

25. Hornick BA, Krester AJ \& Nicklas TA (2008) Menu modeling with MyPyramid food patterns: incremental dietary changes lead to dramatic improvements in diet quality of menus. J Am Diet Assoc 108, 2077-2083.

26. Amano Y, Sugiyama M, Lee JS et al. (2007) Glycemic indexbased nutritional education improves blood glucose control in Japanese adults: a randomized controlled trial. Diabetes Care 30, 1874-1876.

27. United States Food and Drug Administration. Guidance for industry: Diabetes mellitus: developing drugs and therapeutic 
biologics for treatment and prevention. http://www.fda. gov/downloads/Drugs/GuidanceComplianceRegulatory Information/Guidances/ucm071624.pdf (accessed March 2010).

28. UK Prospective Diabetes Study Group (1998) Intensive bloodglucose control with sulphonylureas or insulin compared with conventional treatment and risk of complications in patients with type 2 diabetes (UKPDS 33). Lancet 352, 837-853.

29. Stettler C, Allemann S, Juni P et al. (2006) Glycemic control and macrovascular disease in types 1 and 2 diabetes mellitus: meta-analysis of randomized trials. Am Heart $J$ 152, 27-38.
30. Selvin E, Marinopoulos S, Berkenblit G et al. (2004) Meta-analysis: glycosylated hemoglobin and cardiovascular disease in diabetes mellitus. Ann Intern Med 141, 421-431.

31. The ADVANCE Collaborative Group (2008) Intensive blood glucose control and vascular outcomes in patients with type 2 diabetes. $N$ Engl J Med 358, 2560-2572.

32. Flood A, Subar AF, Hull SG et al. (2006) Methodology for adding glycemic load values to the National Cancer Institute Diet History Questionnaire database. J Am Diet Assoc 106, 393-402. 